\title{
COVID-19 Imperils Access to Health and Human Services in El Paso, Texas and New York City: Perspectives from Hispanic Parents
}

\author{
Eva Margarita Moya ${ }^{1}$ (D) Carolina Zamore ${ }^{1,3} \cdot$ Lourdes Maria Perez $^{2} \cdot$ Kelly Tellez $^{1,3} \cdot$ Alondra Avila $^{1}$. \\ Abraham Aragones ${ }^{3}$
}

Received: 4 January 2021 / Revised: 1 April 2021 / Accepted: 5 April 2021 / Published online: 26 April 2021

(C) W. Montague Cobb-NMA Health Institute 2021

\begin{abstract}
Low-income Hispanic communities are disproportionately impacted by the COVID-19 pandemic through exacerbated financial vulnerabilities and health challenges. The aim of this study is to assess and compare the self-reported impact and challenges caused by COVID-19 in Mexican-origin parents in New York City (NYC), NY and El Paso, TX. Data is based on routine followup calls used to assess uptake of the HPV vaccine and COVID-19 concerns conducted between March and August 2020. Three salient themes emerged: (1) financial insecurities; (2) emotional distress associated with COVID-19; and (3) limited access to health and human services. This study revealed increased financial insecurities and emotional distress, and disruptions to health and human services to low-income Mexican-born parents during the pandemic.
\end{abstract}

Keywords Human papilloma virus $\cdot$ Hispanic parents $\cdot$ Primary healthcare $\cdot$ Low socioeconomic status $\cdot$ COVID-19

\section{Introduction}

The USA has reported 11,136,253 positive cases and 246,232 deaths related to COVID-19 as of November 17, 2020, the highest number recorded globally $[1,2]$. Federal and statelevel policies included school closures, stay-at-home orders, increased access to testing, and treatment to control the coronavirus's spread. Despite these actions, low-income communities of color are disproportionately affected by this pandemic, as demonstrated by the higher infection rates, hospitalization, and mortality [3-6].

The COVID-19 infection trajectory has provided valuable insight to states with densely populated and ethnically diverse cities in New York and Texas. Hispanics in NYC had the highest age-adjusted death rate, 22.8 per 100,000 individuals, during the early phase of the pandemic and continue to be disproportionately impacted [7]. El Paso is predominantly

Eva Margarita Moya emmoya@utep.edu

1 University of Texas at El Paso Department of Social Work, College of Health Sciences, El Paso, TX, USA

2 Pennsylvania State University Department of Biobehavioral Health, University Park, PA, United States

3 Memorial Sloan Kettering Cancer Center, Immigrant Health \& Cancer Disparities Center, New York, NY, USA composed of Hispanic individuals (82.9\%) with a population estimate of 839,238 [8] and is a binational city situated across the border from Ciudad Juarez, Mexico and Dona Ana County in New Mexico. A total of 76,075 positive cases and 782 COVID-19-related deaths have been reported, with $93 \%$ of the cases attributed to Hispanics [9-11], becoming a major hotspot of COVID-19 infections with 89.33 cases per 1000 individuals [12]. Hispanics' vulnerability to COVID-19 may be attributed to low income, limited access to healthcare, lack of health insurance, and higher rates of underlying health conditions.

\section{Hispanics and COVID-19}

Hispanics constitute $18.5 \%$ of the US population [10] and account for $29.2 \%$ of reported COVID-19 cases and $16.6 \%$ of related deaths [11]. COVID-19 disproportionately impacted Hispanics by exacerbating preexistent health and socioeconomic disparities. A survey shows that US and foreign-born Hispanic workers were more likely than non-Hispanic workers to have lost jobs from February to May 2020. Unemployment disparities were higher for Hispanic women, immigrants, young adults, and those with less education [13]. Furthermore, in April 2020, Hispanics households with an income of less than $\$ 35,000$ per year reported higher degrees of psychological distress [14]. Growing evidence suggests 
COVID-19-related job loss, food, and housing insecurities have exacerbated well-established health disparities in lowincome communities with preexisting conditions and barriers to care $[4-6,13,14]$.

Immigrant families may be at higher risk for missed vaccines and, consequently, outbreaks of vaccine-preventable diseases after the pandemic due to delayed treatment-seeking behaviors, language barriers, lack of health insurance and health providers, fear of discrimination, and irregular immigration status [15-18]. Restrictive immigration policy changes could deter the use of public assistance and contribute to worse COVID-19 outcomes among non-eligible and eligible immigrant families. In particular, the recent expansion of public charge criteria could increase COVID-19 disparities among immigrant families who dis-enroll from critical food, health, and housing assistance programs out of fear, whether or not the rule applies to them [19-21]. In Texas, there has been a decrease in child vaccination rates in 2020 compared to 2019 [22]. Similarly, a decrease in routine childhood vaccine administration was most significantly observed during the 2 nd week of April, with a 96\% decrease in immunizations administered to 2-18-year-old children compared to 2019. Additionally, HPV vaccination dropped by $73 \%$ compared to February 2020 [23, 24]. The current HPV vaccination rates in males and females do not meet the NY or Texas state immunization goals [22]. Studies are needed to measure the multi-faceted impact of the COVID-19 pandemic on "noncitizens" who are uninsured, ineligible for comprehensive economic assistance, and likely to use emergency care services or go without care [25]. Mexican families with adolescents may be experiencing the compounding impact of school closures, stay-at-home mandates, institutional barriers to care, and economic safety nets influenced by economic disparities and restrictive immigration policies. Thus, this study aims to assess and compare the self-reported impact and challenges caused by COVID-19 in Mexican-origin, Hispanic parents in El Paso, TX, and New York City, NY.

\section{Methods}

This is a cross-sectional survey nested in a cohort study of Mexican-origin parents and guardians of young adolescents ages 11-17 years recruited from NYC and El Paso. Parents were invited to participate if they selfreported the following: (1) being of Mexican-origin, (2) Spanish as their primary language, and (3) had one child ages 11-17 who had not received/completed the HPV vaccine series.

Community Health Outreach Specialist (CHOS) approached participants attending the Ventanilla de Salud (VDS) or Heath Station at their local Mexican Consulate. The VDS program is a binational collaboration between government, non-profit, and private agencies to increase access to healthcare, low-income, and immigrant communities.

Eligible parents consented to the study completed a baseline assessment that included education, gender, birthplace, and length of time in the USA for the participant and child. Each participant received an incentive of $\$ 10$ for their time.

During routine follow-up calls collected between March and August 2020, CHOS assessed COVID-19 concerns and connected them to local health and human service resources. The open-ended question "Given the current COVID-19 situation, how has the situation affected your work life, personal life, or otherwise?" was posed, and CHOS summarized parents' overall concerns regarding their current living situation. The Institutional Review Board approved this study at both institutions.

\section{Analysis}

Using IBM SPSS Statistics for Windows (version 26.0) [26], descriptive analyses were used to evaluate and compare the parent and child's demographics and assess the parents' reported COVID-19 concerns.

Analysis of qualitative data was guided by the open-ended question assessed during routine follow-up. The intercoder reliability process by Hruschka et al. [27] was used to achieve higher reliability and reduce errors in the coding process. A qualitative coding manual adapted from Saldana [28] was prepared to standardize the qualitative data coding process. Three coders independently employed a pre-coding technique organized through Microsoft Excel to filter information through highlighting, underlining, or coloring salient words and/or phrases in individual participant responses [28]. Data were then interpreted by creating preliminary codes using affective methods (emotion and value coding) and elemental methods (descriptive and in vivo coding). Subsequently, triangulation was conducted to reduce bias and enhance intercoder reliability [29]. Final codes and categories were generated through collaboration among three coders and were presented to the research team for theme extraction. Disagreements were discussed and resolved during team meetings. Using IBM SPSS Statistics, results were quantified using standard frequency analysis to display the prevalence of themes in both samples' themes.

\section{Results}

The characteristics of the parents and child are shown in Table 1.

Over $95 \%$ of the parents in NYC reported having a concern regarding lack of income and dealing with stress and anxiety related to the pandemic. Additional concerns reported by NYC parents were housing insecurities (85.7\%), food insecurities $(73.8 \%)$, and concern of being exposed to the COVID- 
Table 1 Characteristics of the Parent and their child

New York N (\%)

El Paso N (\%)

Parent Sex

Female

Male

$31(91.2)$

$61(98.4)$

Parent Age (M)

$3(8.8)$

1 (1.6)

Country of Birth

37.9

41.7

Mexico

34 (100)

$47(75.8)$

United States

$-$

14 (22.6)

Education

$<8$ th grade

$16(47.1)$

$13(21)$

$\geq 8$ th Grade

$18(52.9)$

49 (79)

Employed*

Yes

14 (41.1)

$31(50)$

No

9 (26.4)

$26(41.9)$

Years since Migrated to U.S.

$<5 \mathrm{y}$

6-9 y

10-15 y

$-$

7 (11.3)

2 (5.9)

$5(8.1)$

$>15 \mathrm{y}$

$12(35.3)$

$10(16.1)$

$20(58.8)$

23 (37.1)

Years Living in Current State

$<5 \mathrm{y}$

$-$

$6(9.7)$

$4(11.8)$

$6(9.7)$

$10-15 \mathrm{y}$

$10(29.4)$

12 (19.4)

$>15 \mathrm{y}$

20 (58.8)

$28(45.2)$

Child Sex

Female

15 (44.1)

28 (54.8)

Male

19 (55.9)

34 (45.2)

Child Age (M)

12.2

12.8

Country of birth

Mexico

United States

19 virus (71.4\%). Parents in El Paso reported having concerns regarding lack of income (35.7\%), dealing with stress and anxiety caused by COVID-19 (31.6\%), exposure to COVID19, and food insecurity (24.5\%). Three themes emerged: (1) financial insecurities, (2) emotional distress associated with COVID-19, and (3) access to health and human services. Three participants in the El Paso sample reported no concerns, whereas none in the NYC sample specifically reported having no concerns. Qualitative results are discussed and interpreted below by frequency distribution analysis of themes (shown as percentages) and salient quotes that arose during coding.

\section{Financial Insecurities}

Participants described financial insecurities as food, utilities, and housing that resulted or were exacerbated by the pandemic. High financial insecurity was expressed by both NYC (94.1\%) and El Paso (61.3\%). Insecurities in paying utilities were salient $(88.2 \%$ and $59.7 \%$, respectively), and predominantly reported to be caused by unemployment. Participants elaborated on the financial hardships of working part-time or having one household member working, impacting income reduction. Housing insecurities were more prevalent in NYC (47.1\%) than El Paso (4.8\%), possibly due to the implications of the NYC eviction moratorium and future rent payments. Food insecurities were similar for both samples, $14.7 \%$ and $16.1 \%$, respectively. Still, they were often described in NYC as insecurity of future food supply where "rationing" was needed, whereas, in El Paso, it was due to greater demand for food as the "children eat all day." 


\section{Emotional Distress Associated with COVID-19}

Exposure to infection, feelings of confinement, virtual schooling, and lack of support systems associated with COVID-19 contributed to $76.5 \%$ and $67.7 \%$ of the participants in NYC and El Paso, respectively, experiencing emotional distress. Concerns of exposure to COVID-19 were salient in NYC (52.9\%) and El Paso (38.7\%). Participants described inadequate compliance with social distancing guidelines by others. One participant stated, "I see that other people are becoming relaxed with the guidelines" (translated from Spanish: Yo veo que otra gente se esta poniendo floja con los pasos necesarios). Participants described their emotional distress as nervous, anxious, stressed, tired, and sad, and were often exacerbated by financial insecurities. Some participants also felt "encerrados" or "confined" to their homes with less access to social support systems due to social distancing.

\section{Access to Health and Human Services}

A total of $88.2 \%$ and $43.5 \%$ of participants in NYC and El Paso reported disruptions to health and human services. NYC participants highlighted delays in HPV vaccination (70.6\%) and community resources usage or avoidance $(44.1 \%)$. Notably, the NYC sample reported having challenging experiences $(38.2 \%)$ when using community resources such as food pantries. One participant elaborated: "they notify us last minute, and when you arrive [to the food pantry], there are long lines, and not everyone gets food, it's not worth going." (translated from Spanish: Nos avisan a última hora, cuando llegas hay bastante fila y después no les toca a todos. No vale la pena ir). Another described discomfort at the lack of social distancing guidelines that did not "give me space" (translated from Spanish: no me dan mi espacio) while waiting in line. Compared to the usage of community resources in El Paso (25.8\%), there were fewer challenging experiences (1.6\%) and were described as helpful and resourceful. Both samples viewed the HPV vaccination as "unnecessary" during the pandemic. HPV vaccination delays were contributed to financial insecurities; one reported: "If I don't have money to buy them food, how am I going to consider vaccination?" Disruption to primary care was attributed to closed clinics and avoiding health-related visits due to exposure of COVID-19. One participant reported not feeling safe going to the hospital: "They [health providers] don't do anything for us, we'd only go to die" (translated from Spanish: No hacen nada para nosotros, solo iríamos a morir).

\section{Discussion}

Comparable to the flu pandemic, this study found similar social determinants of health emerge surrounding Hispanic communities, specifically, stress, social support, food, and financial insecurity [30]. Both El Paso and NYC reported concerns surrounding income instability due to unemployment due to economic closure and stay at home mandates. Financial insecurity prevents the attainment of basic human needs such as food, housing security, and healthcare access, which can lead to additional stress, exacerbating health inequalities and adverse health outcomes [31]. Furthermore, both cities reported emotional distress attributed to the pandemic, which may have been heightened and influenced by prolonged stress due to insecurities, isolation, and constant fear of COVID-19 exposure. These findings reflect current data on Hispanics as vulnerable populations experiencing higher emotional distress caused by the pandemic, predicting depressive symptomatology [32].

This study found that both sample participants predominately sought and utilized community-based assistance programs during the pandemic to stay afloat. This sample is predominantly composed of Mexican-origin Spanish speakers who face significant disadvantages in accessing health and human services due to barriers caused by immigration policies, language and literacy, and discrimination [33]. During COVID-19, there has been an increase in reliance on social resources like federal relief programs, commonly not qualified by immigrants [34]. In today's political climate, foreign-born immigrants face the dilemma of social exclusion, which discourages the use of social and economic safety nets. In dense immigrant cities like New York and El Paso, increased funding of federal, state, and community-based resources could play an essential role in mitigating COVID-19 disparities and negative experiences for populations who exclusively rely on these resources for relief.

In both NYC and El Paso, clinic closures and parental concerns of potentially exposing their children to COVID-19 during well-care visits could be contributing to delays in vaccination. State, city, and school-level immunization campaigns need to ensure that immigrant and at-risk families with adolescents feel safe utilizing immunization services in their area due to the likelihood of missed appointments and additional barriers to care during the pandemic. However, our study navigated participants to resources such as food pantries, federally qualified health centers, vaccination clinics, and domestic violence services specific to COVID-19 times. Beyond the scope of our research question, we consider exploring the impacts of using direct navigational services that specifically serve these communities.

The study has several limitations when interpreting the results. These include the demographic composition, sample size, methods, and representations of findings. Given the small sample, the results may not be generalizable or transferable to understanding the overall experience of Mexicanorigin parents. Additionally, limitations of the investigators' inability to ensure the reliability of the qualitative responses as 
these were short phone interviews. Even with such limitations, the study provides insights into the limited literature and research in these areas.

\section{New Contribution to the Literature}

This study revealed increased financial insecurities, emotional distress, and disruption to health and human services to lowincome Mexican parents during the pandemic. Financial insecurities and emotional distress may lead to negative mental, physical, and health outcomes as displayed by healthcare and social service avoidance behaviors such as disruption in immunization and HPV vaccine uptake. Services focusing on this population should explore and consider how economic, social, and political barriers may disrupt the decision-making of immunization and HPV vaccine uptake of Mexican-born parents.

Acknowledgements We want to thank our intern Alejandra Rivera and all the staff members from our sites at Memorial Sloan Kettering Cancer Center, The University of Texas at El Paso, Alivio Medical Center and Research, Education, and Access to Health Care (R.E.A.C.H.) for all of their efforts in data collection.

Availability of Data and Material Not applicable.

Code Availability Not applicable.

Author Contribution Moya, Zamore, Perez, Tellez, and Avila contributed with the acquisition of data, development of the manuscript, analysis, and interpretation of data, and conducted a critical revision of the manuscript. The last author contributed to the study conception and design and development of the manuscript and conducted a critical revision of the manuscript.

Funding This study was funded by the National Institute on Minority Health and Health Disparities under the grant number R011MD011508.

\section{Declarations}

Conflict of Interest The authors declare no competing interests.

\section{References}

1. CDC. Coronavirus disease 2019 (COVID-19) in the U.S. Centers for Disease Control and Prevention. CDC 2020. https://covid.cdc. gov/covid-data-tracker/\#cases_casesinlast7days

2. Mortality Analyses. Johns Hopkins Coronavirus Research Center 2020. https://coronavirus.jhu.edu/data/mortality

3. Health Equity Considerations and Racial and Ethnic Minority Groups. CDC 2020. https://www.cdc.gov/coronavirus/2019-ncov/ need-extra-precautions/racial-ethnic-minorities.html

4. Gross $\mathrm{CP}$ et al: Racial and ethnic disparities in population level COVID-19 mortality. MedRxIV 2020. https://doi.org/10.1101/ 2020.05.07.20094250

5. Oppel RA et al: The fullest look yet at the racial inequality of coronavirus. The New York Times 2020. https://www.nytimes. com/interactive/2020/07/05/us/coronavirus-latinos-africanamericans-cdc-data.html action $=$ click $\&$ module $=$ Top $\%$ 20Stories\&pgtype $=$ Homepage

6. Rodriguez-Diaz CE, Guilamo-Ramos V, Mena L, Hall E, Honermann B, Crowley JS, et al. Risk for COVID-19 infection and death among Latinos in the United States: examining heterogeneity in transmission dynamics. Annals of Epidemiology. 2020;52:46-53.e2.

7. COVID-19: Data. NYC Health 2020. https://www1.nyc.gov/site/ doh/covid/covid-19-data.page

8. U.S. Census Bureau QuickFacts: El Paso County, Texas. CB 2019. https://www.census.gov/quickfacts/elpasocountytexas

9. City/County of El Paso COVID-19 Results. El Paso Strong 2020. http://epstrong.org/results.php

10. U.S. Census Bureau QuickFacts: United States. CB 2019. https:// www.census.gov/quickfacts/fact/table/US/RHI725219

11. CDC. Coronavirus disease 2019 (COVID-19) in the U.S. Centers for Disease Control and Prevention. CDC 2020. https://covid.cdc. gov/covid-data-tracker/\#demographics

12. CDC. United States COVID-19 cases and deaths by county in the U.S. Centers for Disease Control and Prevention. CDC 2020. https://covid.cdc.gov/covid-data-tracker/\#county-map

13. Kochhar R: Hispanic women, immigrants, young adults, those with less education hit hardest by COVID-19 job losses. Pew Research Center 2020. https://www.pewresearch.org/fact-tank/2020/06/09/ hispanic-women-immigrants-young-adults-those-with-lesseducation-hit-hardest-by-covid-19-job-losses/

14. Golestaneh L, et al. The association of race and COVID-19 mortality. The Lancet. 2020;25.

15. Truman BI, Tinker T, Vaughan E, Kapella BK, Brenden M, Woznica CV, et al. Pandemic influenza preparedness and response among immigrants and refugees. American Journal of Public Health. 2009;99:S278-86.

16. Quinn SC, Kumar S, Freimuth VS, Musa D, Casteneda-Angarita N, Kidwell K. Racial disparities in exposure, susceptibility, and access to healthcare in the US H1N1 influenza pandemic. American Journal of Public Health. 2011;101(2):285-93.

17. Placzek H, Madoff L: Effect of race/ethnicity and socioeconomic status on pandemic H1N1-related outcomes in Massachusetts. American Journal of Public Health 2014; 104(1).

18. Schoch-Spana M, et al. Stigma, health disparities, and the 2009 H1N1 influenza pandemic: how to protect Latino farmworkers in future health emergencies. Biosecurity and Bioterrorism: Biodefense Strategy, Practice, and Science. 2010;8(3):243-54.

19. Vargas ED, Sanchez GR, Juárez MD. The impact of punitive immigrant laws on the health of Latina/o populations. Polit Policy. 2017;45(3):312-37.

20. Zallman L et al: Implication of changing public charge immigration rules for children who need medical care. JAMA Pediatr 2019; 173(9).

21. Batalova $\mathrm{J}$ et al: Chilling effects: the expected public charge rule and its impact on legal immigrant families' public benefits use. Migration Policy Institute 2018.

22. Immunization Unit. Texas Department of State and Health Services 2020. https://www.dshs.state.tx.us/immunize/

23. Langdon-Embry M, Papadouka V, Cheng I, Almashhadani M, Ternier A, Zucker JR: Notes from the field: rebound in routine childhood vaccine administration following decline during the COVID-19 pandemic-New York City 2020. Morbidity and Mortality Weekly Report. https://www.cdc.gov/mmwr/volumes/ 69/wr/mm6930a3.htm

24. Hoffman J: Vaccine rates drop dangerously as parents avoid doctor's visits. New York Times 2020. https://www.nytimes.com/ 2020/04/23/health/coronavirus-measles-vaccines.html 
25. Health Coverage of Immigrants. KFF 2020. https://www.kff.org/ racial-equity-and-health-policy/fact-sheet/health-coverage-ofimmigrants/

26. IBM SPSS Statistics for Windows, Version 26.0. IBM Corp 2017.

27. Hruschka DJ, Schwartz D, St.John DC, Picone-Decaro E, Jenkins RA, Carey JW. Reliability in coding open-ended data: lessons learned from HIV behavioral research. Field Methods. 2004;16: 307-31.

28. Saldana J: The coding manual for qualitative researchers Third Edition. SAGE Publications 2015.

29. Kohlbacher F: The use of qualitative content analysis in case study research. Forum: Qualitative Social Research 2006; 7(21).

30. Wilkinson RG, Marmot M (Eds): Social determinants of health: the solid facts. World Health Organization 2003.

31. Benzeval $\mathrm{M}$ et al: How does money influence health? Joseph Rowntree Foundation 2014. https://www.jrf.org.uk/report/howdoes-money-influence-health
32. Fitzpatrick KM et al: Facing new fears during the COVID-19 pandemic: the state of America's mental health. Journal of Anxiety Disorders 2020; 102291.

33. Martinez O, et al. Evaluating the impact of immigration policies on health status among undocumented immigrants: a systematic review. Journal of Immigrant and Minority Health. 2013;17:947-70.

34. Chishti M, Bolter J: Vulnerable to COVID-19 and in frontline jobs, immigrants are most shut out of U.S. Relief. Migration Policy Institute 2020. https://www.migrationpolicy.org/article/covid19immigrants-shut-out-federal-relief

Publisher's Note Springer Nature remains neutral with regard to jurisdictional claims in published maps and institutional affiliations. 